\title{
Pendampingan Penggunaan Latex Untuk Penyesuaian Format Artikel Bagi Dosen Dan Mahasiswa Prodi PGSD FKIP Universitas Mataram
}

\author{
Muhammad Erfan*, Mohammad Archi Maulyda, Vivi Rachmatul Hidayati, Lalu \\ Hamdian Affandi, Sukardi \\ Universitas Mataram, Indonesia \\ Email: muhammaderfan@unram.ac.id, archimaulyda@unram.ac.id, \\ vivirachma@unram.ac.id, hamdian.fkip@unram.ac.id, sukardi@unram.ac.id
}

\begin{abstract}
ABSTRAK
Kegiatan ini bertujuan untuk melatih dosen dan mahasiswa khususnya di lingkungan program studi pendidikan guru sekolah dasar dalam penyiapan dan penyesuaian format artikel (template) menggunakan Program LaTeX, serta mengetahui respons peserta pelatihan terhadap pelaksanaan kegiatan. Kegiatan ini dilaksanakan melalui metode penyuluhan dan pendampingan secara dalam jaringan (daring). Di awal kegiatan peserta diberikan pre-test untuk mengetahui sejauh mana kemampuan awal peserta pelatihan dalam penyesuaian format artikel (template) dan di akhir kegiatan peserta pelatihan juga diberikan post-test dan angket respons mengenai tingkat kepuasan peserta pelatihan terhadap kegiatan yang telah dilaksanakan. Hasil respons peserta sangat positif berkaitan dengan pemahaman peserta kegiatan dalam penggunaan program LaTeX dalam proses penyesuaian format artikel (template) dengan persentase kenaikan sebesar 6,4\% dari 76,9\% menjadi 83,3\%. Umpan balik dari peserta pelatihan yaitu sebagian besar peserta mengharapkan terdapat pelatihan dan pendampingan selanjutnya dengan waktu dan intensitas pendampingan yang lebih panjang.
\end{abstract}

Kata kunci: pendampingan, LaTeX, template, artikel

\section{PENDAHULUAN}

Kegiatan publikasi hasil penelitian merupakan bagian dari salah satu poin Tridarma Perguruan Tinggi yaitu bagian melaksanakan penelitian (Fathurrahman \& Muhtarom, 2019; Yamin, 2018). Dosen sebagai pelaksana Tridarma Perguruan Tinggi juga wajib untuk melakukan publikasi hasil penelitian di jurnal nasional terakreditasi maupun di jurnal internasional bereputasi di bidangnya apabila dosen tersebut ingin naik jabatan ke jenjang akademik yang lebih tinggi (Hartono et al., 2019). Oleh karena itu, sudah menjadi kewajiban dosen untuk selalu belajar, meneliti dan meningkatkan jumlah publikasi hasil temuan dari kajian atau penelitian dalam bentuk artikel ilmiah dan berdasarkan bukti agar sedikit banyak bisa bermanfaat bagi khazanah ilmu pengetahuan maupun masyarakat luas.

Artikel ilmiah yang ditulis oleh mayoritas dosen yang ada di program studi pendidikan guru sekolah dasar fakultas keguruan dan ilmu pendidikan Universitas Mataram umumnya masih menggunakan program pengolah kata dari Microsoft Office yaitu Microsoft Word. Dalam praktiknya, Microsoft Office sebetulnya memiliki kelemahan dalam proses pengerjaannya (Soffar, 2015). Microsoft Office yang dipasang disarankan harus software original sehingga tidak sedikit pihak yang menggunakan software Microsoft Office bajakan. Microsoft Office juga memerlukan update secara berkala dan lebih mengandalkan fitur-fitur dalam penggunaannya. Format penulisan pada Microsoft Word sangat sulit untuk beradaptasi 
dan bahkan jika versi Microsoft Office yang digunakan berbeda antara dua komputer, maka dimungkinkan format tulisan juga akan berubah. Selain itu, Microsoft Word sebagai program pengolah kata dari Microsoft Office memerlukan Random Access Memory (RAM) yang besar apabila digunakan untuk menulis persamaan-persamaan matematika yang kompleks.

Selain Microsoft Office, platform lain yang dapat membantu penulisan artikel ilmiah bagi para dosen adalah LaTeX (Hartono et al., 2019). LaTeX merupakan software open-source yang dapat membantu untuk menyiapkan dan menulis dokumen ilmiah dan teknis (Pakin, 2005). Latex juga merupakan bahasa pemrograman dalam penulisan dokumen yang biasa digunakan dokumen yang memuat banyak persamaan matematika (Shiddiq, 2018). LaTeX memiliki beberapa keunggulan dibandingkan dengan perangkat lunak lainnya seperti Microsoft Word. Keunggulan-keunggulan tersebut antara lain adalah LaTeX dapat diakses secara gratis, LaTeX juga membolehkan pengguna untuk lebih fokus pada kualitas konten dokumen daripada format dan hal detail lainnya seperti jenis font dan warna tulisan. LaTeX memudahkan pengguna untuk mengatur dan menangani dokumen yang lebih kompleks, serta LaTeX juga mampu mengatur dan memfasilitasi dokumen yang terdapat banyak persamaan-persamaan matematis (Roberts, 2011).

Di samping keunggulan-keunggulan yang telah dijelaskan, LaTeX menuntut penggunanya untuk menggunakan sedikit bahasa pemrograman dalam command atau instruksi di LaTeX. Oleh sebab itu, diperlukan pelatihan dalam menguasai minimal dasar-dasar dari bahasa pemrograman pada LaTeX. Kegiatan ini merupakan kegiatan awal dalam memperkenalkan LaTeX sebagai typesetting software yang dapat menghasilkan output dokumen berkualitas tinggi selain Microsoft Word yang umumnya digunakan oleh dosen maupun mahasiswa di lingkungan Program Studi Pendidikan Guru Sekolah Dasar Universitas Mataram.

\section{METODE PELAKSANAAN}

Metode pelaksanaan kegiatan ini berupa pendampingan untuk meningkatkan kemampuan dosen dan mahasiswa di lingkungan program studi pendidikan guru sekolah dasar dalam penulisan dan penyesuaian format artikel ilmiah, terutama dalam pelatihan menggunakan LaTeX yang memerlukan pemahaman mengenai bahasa pemrograman. Pendampingan ini bertujuan agar peserta kegiatan mendapatkan pengetahuan terhadap beberapa program pengolah kata dalam menulis artikel ilmiah, penyesuaian format artikel ilmiah (template) sebelum artikel diserahkan (submit) ke jurnal, ataupun bahan ajar atau buku ajar. Secara umum kegiatan yang dilakukan adalah sebagai berikut: (1) membuat modul petunjuk penggunaan LaTeX untuk penyesuaian format artikel ilmiah (template) serta untuk penulisan bahan ajar, memberikan pendampingan penggunaan LaTeX untuk penyesuaian format artikel ilmiah (template) serta untuk menulis artikel ilmiah, (3) menyusun angket respons mengenai LaTeX sebagai program pengolah kata dan manfaatnya dalam kegiatan pendampingan yang dilaksanakan, mengumpulkan data dengan angket respons serta menganalisis hasilnya.

\section{HASIL DAN PEMBAHASAN}

Kegiatan pendampingan penggunaan LaTeX untuk penyesuaian format artikel bagi dosen dan mahasiswa Program Studi Pendidikan Guru Sekolah Dasar Fakultas Keguruan dan Ilmu Pendidikan Universitas Mataram dimulai dari tahap persiapan pendampingan. Pada tahapan ini tim pelaksana kegiatan melakukan koordinasi dengan pihak program studi, beberapa dosen dan 
antara anggota tim. Koordinasi dilakukan untuk memastikan tanggal pelaksanaan pendampingan, persiapan sarana prasarana seperti Aplikasi Zoom dan link Zoom Meeting yang akan digunakan pada saat acara dilangsungkan, serta persiapan mengenai materi yang akan disajikan pada kegiatan pendampingan.

\section{Pembuatan Modul Panduan Template Artikel dengan Ms. Word dan LaTex}

Pada tahap ini, tim membuat modul panduan penyesuaian format artikel ilmiah (template) artikel ilmiah menggunakan Microsoft Word dan LaTeX. Modul yang telah dibuat ini disusun dengan menggunakan Program LaTeX dan digunakan sebagai panduan peserta kegiatan terutama pada bagian pengenalan fungsi dan bagian-bagian serta coding-coding atau command-command yang biasanya digunakan dalam penyesuaian format artikel ilmiah (template), pembuatan bahan ajar atau buku ajar.
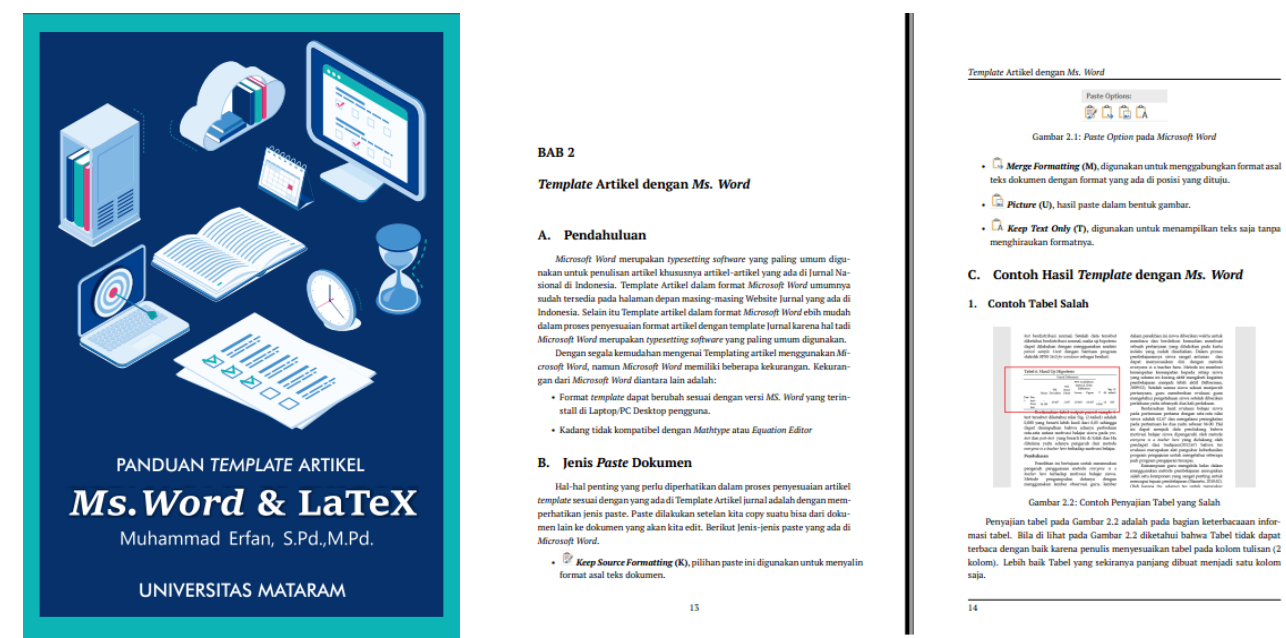

Gambar 1. Modul Panduan Template Artikel dengan Ms. Word dan LaTex

Modul panduan template artikel dengan Ms. Word dan LaTex terbagi menjadi 3 bagian yaitu cara penyesuaian format artikel ilmiah (template)artikel dengan menggunakan Microsoft Word, penyesuaian format artikel ilmiah (template) artikel dengan menggunakan LaTeX, serta panduan publikasi sebagai Editor dan Reviewer pada Open Journal System (OJS) 3.

\section{Memberikan Pendampingan Penggunaan LaTeX}

Kegiatan pendampingan dilakukan secara dalam jaringan dan dilaksanakan pada tanggal 15 November 2020, dengan jumlah peserta sebanyak 20 orang. Kegiatan pendampingan ini dikolaborasikan dengan kegiatan pendampingan peningkatan wawasan kejurnalan civitas akademik program studi pendidikan guru sekolah dasar Universitas Mataram yang dilangsungkan melalui Zoom.

Kegiatan pendampingan ini diisi oleh 3 narasumber yaitu Mohammad Archi Maulyda, S.Pd., M.Pd., Muhammad Erfan, S.Pd., M.Pd., dan Vivi Rachmatul Hidayati, S.Pd., M.Pd. Kegiatan ini juga dimoderatori oleh salah satu narasumber yaitu Vivi Rachmatul Hidayati, S.Pd., M.Pd. di mana ketiga narasumber sama-sama merupakan tim editor dari jurnal Renjana Pendidikan Dasar yaitu salah satu Jurnal Online yang berada di bawah Program Studi PGSD Universitas Mataram. 


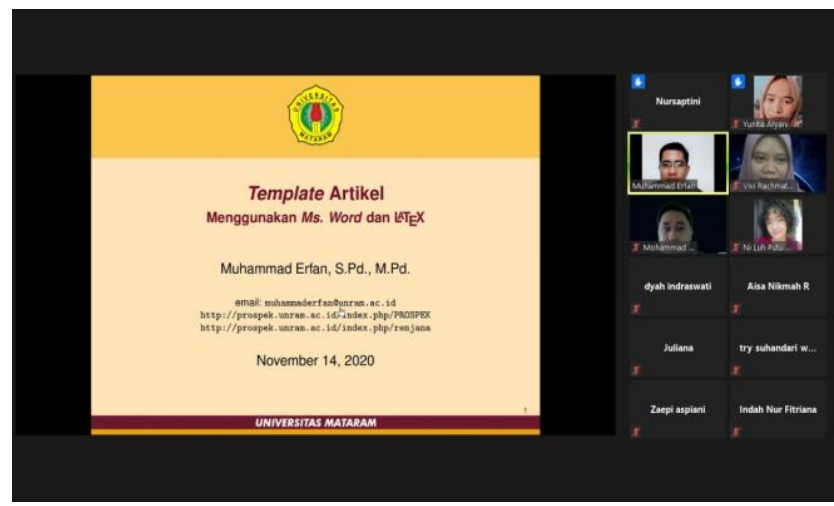

Gambar 2. Kegiatan Pendampingan Penggunaan LaTeX melalui Zoom

Sebelum kegiatan pendampingan dimulai, peserta kegiatan diberikan lembar pre-test di mana peserta diberikan pertanyaan-pertanyaan seputar wawasan kejurnalan. Hal ini dilakukan dengan tujuan untuk mengetahui wawasan kejurnalan peserta sebelum diberikan materi. Acara dibuka oleh moderator. Setelah pembukaan, Mohammad Archi Maulyda memulai penyampaian materi 1 , yakni tentang proses pembuatan akun atau register di portal jurnal online yang menggunakan OJS 3. Dalam hal ini, pemateri memperagakan langsung langkahlangkah registrasi pada jurnal online. Setelah itu, Mohammad Archi Maulyda menjelaskan tata cara mengusulkan artikel ilmiah dengan tombol (button) "new submission". Mohammad Archi Maulyda menjelaskan hal-hal penting yang tidak boleh dilupakan saat submit artikel ilmiah kita di jurnal yang menggunakan OJS 3. Hal-hal tersebut di antaranya adalah (1) Tidak lupa mengunggah article text, (2) Menuliskan family name atau nama belakang dengan benar, (3) Menekan "tab" setelah menuliskan satu keyword, serta (4) Menuliskan seluruh penulis (author) sesuai dengan urut dan secara lengkap.

Narasumber kedua yaitu Muhammad Erfan, S.Pd., M.Pd. menjelaskan mengenai hal-hal yang berkaitan dengan template artikel di jurnal ilmiah. Narasumber juga menjelaskan bahwa proses penyesuaian format artikel (template) merupakan salah satu hal yang harus dilakukan sebelum manuskrip di serahkan (submit) ke suatu jurnal dan menjadi salah satu pertimbangan bagi ketua tim editor dalam menilai kelayakan suatu manuskrip untuk dipublikasikan.

Materi lainnya yang disajikan oleh Muhammad Erfan, S.Pd., M.Pd. adalah mengenai penyesuaian format artikel (template) menggunakan Ms. Word dan LaTeX. Penyesuaian format artikel menggunakan Ms. Word merupakan hal yang sangat mudah dan menjadi pilihan banyak orang serta hampir sebagian besar jurnal ilmiah di Indonesia menggunakan format artikel (template) dalam format Ms. Word. Lebih jauh, pemateri menyampaikan bahwa hal yang perlu diperhatikan berkaitan dengan penyesuaian template selain menyeragamkan manuskrip sesuai dengan kaidah penulisan adalah informasi yang ada pada manuskrip dapat terbaca dengan baik, serta estetika tampilan di jurnal ilmiah.

Materi mengenai penyesuaian format artikel (template) menggunakan LaTeX diawali dengan penjelasan apa itu LaTeX serta kelebihan dan kekurangan LaTeX dan penggunaannya dalam penyesuaian format artikel (template) di jurnal-jurnal yang sudah bertaraf internasional karena hasil atau dokumen yang dihasilkan oleh LaTeX memiliki kualitas dan keteraturan yang tinggi. Selain itu penyesuaian format artikel (template) menggunakan LaTeX lebih menekankan pada bagian-bagian artikel ilmiah pada program LaTeX, perintah-perintah atau command-command yang umumnya digunakan dalam proses penyesuaian format artikel 
(template) menggunakan LaTeX, serta kemungkinan error yang akan terjadi dalam proses penyesuaian format artikel (template) dengan menggunakan LaTeX ataupun pada saat proses compile command-command di LaTeX.

Materi ketiga dalam kegiatan pendampingan disampaikan oleh Vivi Rachmatul Hidayati, S.Pd., M.Pd. berkenaan dengan cara mengunduh artikel dari reviewer dan juga mengunggah hasil revisinya di jurnal yang menggunakan OJS 3. Sebelum itu, Pemateri ketiga juga menjelaskan bahwa setelah proses penyerahan (submit) artikel ilmiah, setiap manuskrip akan melewati seleksi dari pihak editor. Setelah diseleksi, jika dirasa bisa diterima dengan revisi, maka reviewer akan memberikan komentar-komentar yang nantinya akan bisa ditanggapi oleh penulis (author). Selain itu, Pemateri ketiga juga menjelaskan langkah-langkah mengunduh artikel dari proses reviewer sekaligus cara-cara untuk mengunggah artikel yang sudah direvisi oleh penulis (author).

\section{Mengumpulkan Data Respons}

Selain menyiapkan modul dan melakukan kegiatan pendampingan secara daring, tim juga menyusun angket respons peserta mengenai pemahaman peserta kegiatan terhadap paparan materi dari narasumber. Berdasarkan hasil pre-test dan post-tes diperoleh bahwa terdapat peningkatan pemahaman peserta pelatihan penyesuaian format artikel (template) dengan menggunakan LaTeX dari yang semula 76,9\% dari total peserta menjadi 83,3\% peserta yang memahami penyesuaian format artikel (template) dengan menggunakan LaTeX.

Program LaTeX yang lebih menekankan kemampuan coding peserta pelatihan membuat para peserta pelatihan merasa waktu yang diberikan kurang memadai sehingga dari umpan balik kegiatan ini beberapa peserta merasa perlu dilakukan kegiatan susulan untuk memperdalam kemampuan peserta pada penggunaan LaTeX dalam kegiatan proses penyesuaian format artikel ilmiah (template) karena untuk memahami bahasa pemrograman diperlukan waktu yang tidak sedikit (Hartono et al., 2019; Knauff \& Nejasmic, 2014).

\section{KESIMPULAN DAN SARAN}

Berdasarkan uraian kegiatan yang telah dilakukan, dapat disimpulkan bahwa peserta pendampingan sudah memahami penggunaan LaTeX untuk penyesuaian format artikel dan sedikit mengetahui mengenai bagaimana mengoperasikan program tersebut. Selain itu, respons peserta juga sangat baik yang ditunjukkan dengan hasil angket respons di mana hampir sebagian besar respons yang ditunjukkan merupakan respons positif. Peserta pelatihan juga terlihat antusias selama kegiatan pelatihan berlangsung dan banyak dari peserta berpendapat dan meminta agar terdapat kegiatan lanjutan untuk peserta agar dapat menggali lebih jauh mengenai penggunaan program LaTeX dalam proses penyesuaian format artikel ilmiah (template). Saran yang dapat diberikan adalah kegiatan ini agar dapat dilanjutkan dengan memberikan pendampingan dan bimbingan secara berkala atau berupa kegiatan pendampingan lanjutan

\section{UCAPAN TERIMA KASIH}

Ucapan terima kasih penulis persembahkan kepada Universitas Mataram khususnya Program Studi Pendidikan Guru Sekolah Dasar dan Kementerian Pendidikan dan Kebudayaan yang bekerja sama dengan Pusat Pengembangan Sumber Daya Manusia Geominerba BPSDM 
Kementerian Energi dan Sumber Daya Mineral dalam pelaksanaan Pelatihan Dasar Calon Pegawai Negeri Sipil Golongan III.

\section{DAFTAR PUSTAKA}

Fathurrahman, F., \& Muhtarom, A. (2019). Pengaruh Pembinaan Tri Dharma Perguruan Tinggi terhadap Perilaku Dosen sebagai Sumber Daya Manusia Pendidikan. Ilmu Pendidikan: Jurnal Kajian Teori Dan Praktik Kependidikan, 4(1), 45-48.

Hartono, Y., Somakim, S., Dwi Pratiwi, W., Araiku, J., \& Nuraeni, Z. (2019). Pendampingan Penggunaan LaTeX untuk Penulisan Artikel Ilmiah bagi Dosen Universitas PGRI Palembang. Jurnal Anugerah, 1(1), 51-57. https://doi.org/10.31629/anugerah.v1i1.1652

Knauff, M., \& Nejasmic, J. (2014). An Efficiency Comparison of Document Preparation Systems Used in Academic Research and Development. PLOS ONE, 9(12), e115069. https://doi.org/10.1371/journal.pone.0115069

Pakin, S. (2005). The comprehensive LaTeX symbol list. Comprehensive TeX archieve network. Online. http://tug.ctan.org/info/symbols/comprehensive/symbols-a4.pdf

Roberts, A. (2011). Benefits of LaTeX typesetting. Online. https://www.andyroberts.net/writing/latex/benefits

Shiddiq, M. M. (2018). Cara Mudah Menulis Artikel Ilmiah dengan Latex. Online. https://www.haimatematika.com/2018/10/cara-mudah-menulis-artikel-ilmiah.html

Soffar, H. (2015). What are the advantages and disadvantages of Microsoft Word? Online. https://www.online-sciences.com/technology/what-are-the-advantages-anddisadvantages-of-microsoft-word/

Yamin, M. (2018). Kebijakan Literasi untuk Meningkatkan Produktivitas Publikasi di Perguruan Tinggi. JAS-PT Jurnal Analisis Sistem Pendidikan Tinggi, 2(1), 19. https://doi.org/10.36339/jaspt.v2i1.120 